\title{
O processo empreendedor: associando \\ - Business Model Canvas (BMC) ao Life Cycle Canvas (LCC)
}

\section{The entrepreneurial process: connecting business model Canvas (BMC) to life cycle Canvas (LCC)}

Alexandre Magno Silva Filho ${ }^{1}$

Rafael Rodrigues da Silva ${ }^{2}$

Dmitryev Cyreneu da Silva ${ }^{3}$

Marcos Fernando Machado de Medeiros ${ }^{4}$
1 Bacharel em administração pela UFRN, especialista em Marketing estratégico pela UNINTER e mestrando em administração pela UFRN.

2 Doutorando em Administração - PPGA/UFRN rafaelrodges@outlook.com

3 Mestrando em Administração - PPGA/UFRN dmitryev14@gmail.com

4 Doutor em Administração - PPGA/UFRN mfmedeiros@gmail.com

\section{Resumo}

O processo empreendedor envolve desde a concepção de uma ideia até a implementação e gestão do novo negócio. Entre as ferramentas utilizadas nesse processo pode-se destacar o Business Model Canvas (BMC), um quadro de modelo de negócio que contempla as principais áreas que devem ser pensadas. Esta ferramenta baseada na filosofia de gestão visual é amplamente conhecida e a literatura indica que seu uso demonstra contribui para eficiência no processo empreendedor. Desse modo, este artigo teórico propõe uma associação do BMC com a gestão de projetos por meio do Life Cycle Canvas (LCC). A ideia central é mostrar como estas duas ferramentas podem ser associadas, uma em complementaridade à outra, para promover melhores resultados para o negócio, uma vez que a implementação dos projetos originados no BMC pode ser um fator crítico de sucesso para o negócio. Essa associação mostrou que há complementaridade entre as duas ferramentas, ficando o BMC responsável pela fase inicial do processo empreendedor, enquanto o LCC atende à fase final, de gestão dos projetos que levam ao sucesso do negócio.

Palavras-chaves: Processo empreendedor. Business Model Canvas. Life Cycle Canvas.

\begin{abstract}
The entrepreneurial process involves from the conception of an idea to the implementation and management of the new business. Among the tools used in this process can be highlighted the Business Model Canvas (BMC), a framework of business model that contemplates the main areas that must be thought. This tool based on the philosophy of visual management is widely known and the literature indicates that its use demonstrates contributes to efficiency in the entrepreneurial process. Thus, this theoretical article proposes an association of the BMC with the management of projects through the Life Cycle Canvas (LCC). The central idea is to show how these two tools can be associated, one in complementarity to the other, to promote better results for the business, since the implementation of the projects originated in BMC can be a critical success factor for the business. This association showed that here is complementarity between the two tools, leaving the $\mathrm{BMC}$ responsible for the initial phase of the entrepreneurial process, while the LCC attends the final phase of project management that leads to the success of the business.
\end{abstract}

Keywords: Entrepreneurial process. Business Model Canvas. Life Cycle Canvas. 


\section{Introdução}

O cenário atual é caracterizado pelo dinamismo, fruto dos avanços tecnológicos, e pela competitividade (Dornelas, 2011). Logo, vincular a concepção de um negócio à gestão de projetos passou a ser um diferencial para empreendedores e organizações que precisam efetivar as estratégias planejadas para que o negócio tenha sucesso (Hrebiniak, 2006; Jamieson \& Morris, 2007; Kwak \& Anbari, 2009).

Dessa forma, as novas ferramentas baseadas em quadros visuais, ou canvas, foram criadas com o intuito de auxiliar a concepção do negócio bem como sua gestão, simplificando-a (Osterwalder \& Pigneur, 2011; Finocchio, 2013; Veras, 2014; Veras, 2016). Neste contexto, pode-se destacar o Business Model Canvas (BMC) (Osterwalder \& Pigneur, 2011), voltado para o processo de concepção da ideia ou do negócio, o Project Model Canvas (PMC) (Finocchio, 2013) e o Life Cycle Canvas (LCC) (Veras, 2016), ambos aplicados ao gerenciamento de projetos e aderentes ao Guia PMBOK (Project Management Institute [PMI], 2013).

Essas ferramentas baseadas em quadros visuais (canvas) têm proporcionado vantagens para quem os usa, tais como: agilidade para lançamento de estratégias; permite interatividade entre as diversas áreas; permite uma visão holística; melhora a comunicação e a produtividade; contribui para a gestão dos projetos e envolvimento da equipe; e exige objetividade e informações relevantes (Nagamatsu, Barbosa \& Rebecchi, 2014; Glória $\&$ Gonçalves, 2016). Assim como o uso conjunto de dois ou mais modelos ou ferramentas em canvas (em complementaridade) também é sugerido pela literatura (Finocchio, 2013; Zandoval Bonazzi \& Ari Zilber, 2014; Veras, 2014).

Dessa maneira, considerando que "negócios bem-sucedidos, de melhor desempenho, quase sempre dependem de boas estratégias e bons pro- jetos" (Veras, 2014, p. 8), a utilização de modelos e ferramentas baseadas em canvas podem contribuir para que este processo seja mais eficaz. Nesse sentido, o uso em complementaridade de modelos em canvas que suporte todo o processo empreendedor, desde a concepção da ideia aos projetos de implementação de estratégias, pode ser um diferencial de competitividade e sucesso.

Neste sentido, este artigo teórico propõe uma associação do modelo BMC com o LCC, indicando a complementaridade entre essas duas ferramentas para gerar um artefato que pode ser utilizado durante o processo empreendedor. Cabe ressaltar que a literatura apresenta outros modelos baseados em canvas (Finocchio, 2013; Mei, 2015), no entanto optou-se por trabalhar estes dois considerando e escopo e o foco de cada um relacionado ao processor empreendedor.

Para tanto, este artigo apresenta as características principais do BMC e do LCC. Em seguida, indica de que forma estes modelos podem ser integrados. E, por fim, são apontadas as considerações finais e listadas as referências.

\section{Empreendedorismo e o Business Model Canvas (BMC)}

A atividade empreendedora é primordialmente definida pela criação e execução de novas ideias, seja o nascimento de novos negócios ou o desenvolvimento de novos produtos dentro de negócios já existentes (Dornelas, 2011).

Na definição clássica de Schumpeter (1985), empreender é inovar a ponto de criar condições para uma radical transformação de um determinado setor, ramo de atividade ou território, onde o empreendedor atua. Desse modo, percebe-se a capacidade transformadora do empreendedorismo enquanto geração de novas ideias e negócios, além de promover impacto significativo na economia 
do país. Portanto, torna-se necessária a aplicação de conceitos, modelos e ferramentas de gestão que auxiliem o processo empreendedor (Baron \& Shane, 2010; Dornelas, 2011).

De modo geral, o processo empreendedor é composto por fases sequencias que se desenvolvem ao longo do tempo, e, apesar das fases serem apresentadas de forma sequencial, elas podem ser realizadas concomitantemente em algum momento (Baron \& Shane, 2010; Dornelas, 2011). A Figura 1 ilustra as principais fases do processo empreendedor.

Observa-se que para a consecução das fases do processo empreendedor podem ser utilizadas vários modelos e ferramentas de gestão, tais como: análise SWOT, 5W2H, matriz BCG, dentre outras. A partir disso, Osterwalder e Pigneur (2011) desenvolveram uma ferramenta baseada na filosofia da gestão visual conhecido como Business Model Canvas (BMC), que livremente traduzido significa quadro de modelo de negócio. Essa proposta foi pensada para ser de fácil descrição facilitando a discussão de uma ideia ou de um negócio (Osterwalder \& Pigneur, 2011).

Um modelo de negócio possui características diferentes de um plano de negócio. O modelo descreve a lógica de criação do negócio valorizando o sentido do raciocínio e da interconexão entre as partes. Já o plano descreve detalhadamente a forma como o negócio será construído, com etapas, prazos, planilhas de custos, etc (Serviço Brasileiro de Apoio às Micro e Pequenas Empresas [SEBRAE],
2013). Na prática, alguns empreendedores utilizam o BMC na fase inicial do negócio e o plano de negócio para detalhamento da proposta do negócio (Carrasco, Souza Nunes, Cerqueira \& Costa Rosas, 2014).

O BMC permite visualizar as principais funções de um negócio em blocos relacionados que objetivam responder às seguintes questões: "o que fazer?”; “como fazer?"; "para quem?” e "quanto vai custar?" (Osterwalder \& Pigneur, 2011). Nesse sentido, a proposta central do BMC é a possibilidade de visualizar a descrição do negócio, das partes que o compõem, de forma que a ideia sobre o negócio seja facilmente compreendida.

Para Osterwalder e Pigneur (2011), essas áreas cobrem as quatro principais áreas de um negócio: clientes, oferta, infraestrutura e viabilidade financeira. Sendo que a relação das "questões + componentes = bloco do negócio" é descrita pela Figura 2 que ilustra o modelo de negócio.

O lado direito do Quadro está relacionado ao cliente e em como a oferta de valor chegará até ele (segmento de cliente, relacionamento, canais e oferta de valor). O lado esquerdo estabelece as questões estruturais do negócio (atividades principais, parcerias e recursos). E na parte inferior está a perspectiva financeira (estrutura de custos e fontes de receita) (Veras, 2014). A Tabela 1 resume os nove elementos que compõem o BMC.

Quanto a aplicação desse modelo, a literatura apresenta estudos recentes utilizaram o BMC. Nagamatsu, Barbosa e Rebecchi (2014) investiga-

\begin{tabular}{|c|c|c|}
\hline Fase 1 & Fase 2 & Fase 3 \\
$\begin{array}{c}\text { Ideia para novo produto } \\
\text { ou serviço / } \\
\text { ou reconhecimento de } \\
\text { oportunidades }\end{array}$ & $\begin{array}{c}\text { Desenvolver } \\
\text { um plano de } \\
\text { negócio }\end{array}$ & $\begin{array}{c}\text { Captação dos } \\
\text { recursos } \\
\text { necessários }\end{array}$ \\
gestão de um \\
negócio de \\
sucesso
\end{tabular}

Figura 1: As fases do processo empreendedor

Nota: Elaboração própria a partir de Baron e Shane (2010, p. 16) e Dornelas (2011, p. 33). 


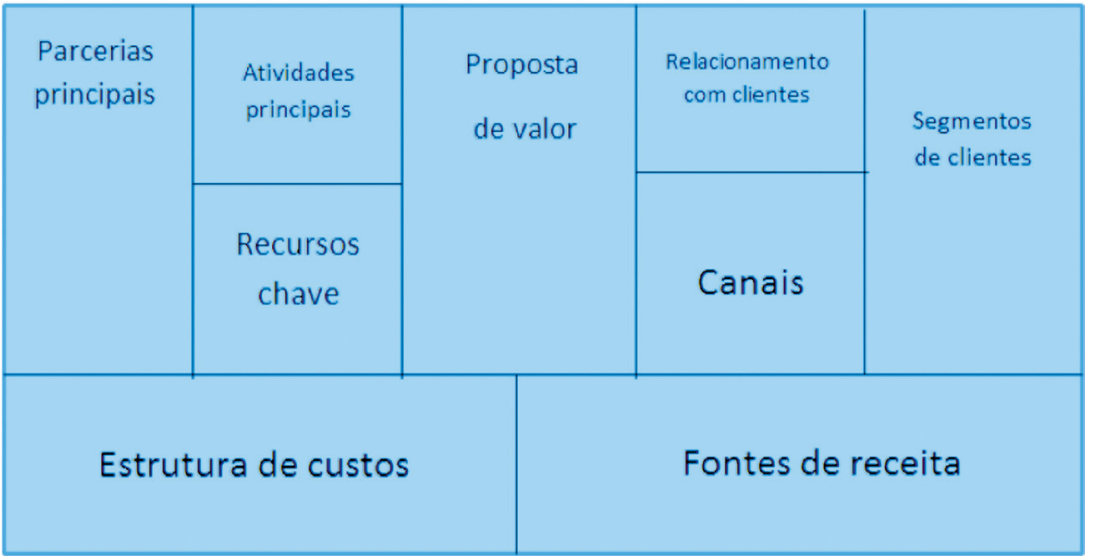

Figura 2: Modelo do BMC

Nota: Elaboração própria a partir de Osterwalder \& Pigneur, 2011.

ram a aplicação do BMC em startups e verificaram a ferramenta proporcionou vantagens quando aplicada a esse tipo de negócio, a saber: promove agilidade de lançamento de estratégias e a visu- alização dos possíveis resultados; mostrou-se mais eficiente do que outros modelos, ou até mesmo em relação ao Plano de Negócio; apresenta interatividade entre 15 áreas do modelo; a apresentação visual proporciona facilidades para alteração; e também foi indicada a capacidade de resposta rápida às simulações ou análises de viabilidade. Carrasco et al. (2014) avaliaram a visão de empreendedores sobre o uso do BMC com empresas incubadas em diferentes fases do negócio. Percebeu-se que o BMC, "quase na totalidade das opiniões, foi muito claro e relevante no auxílio da visualização dos diversos modelos de negócio” (p. 16).

Tabela 1: Resumo dos elementos do BMC

\begin{tabular}{|c|c|c|}
\hline Componente & Descrição & Pergunta-chave \\
\hline $\begin{array}{l}\text { Segmento } \\
\text { de clientes }\end{array}$ & $\begin{array}{c}\text { Descrição dos grupos de pessoas ou } \\
\text { organizações que o modelo de negócio a ser } \\
\text { desenvolvido buscará alcançar. }\end{array}$ & $\begin{array}{l}\text { Para quem o modelo de negócio } \\
\text { pretende criar valor? }\end{array}$ \\
\hline Proposta de valor & $\begin{array}{l}\text { Aspecto intangível do seu modelo de negócio } \\
\text { que fará o cliente optar em detrimento de outro } \\
\text { presente no mercado. }\end{array}$ & $\begin{array}{l}\text { Qual valor o modelo de negócio } \\
\text { entregará ao segmento de clientes. }\end{array}$ \\
\hline Canais & $\begin{array}{c}\text { Os pontos de contato entre empresas e clientes, } \\
\text { antes, durante e depois da compra. }\end{array}$ & $\begin{array}{c}\text { Como a empresa comunicará sua } \\
\text { proposta de valor e como a entregará } \\
\text { ao cliente? }\end{array}$ \\
\hline $\begin{array}{l}\text { Relacionamento } \\
\text { com clientes }\end{array}$ & $\begin{array}{c}\text { Formas de relacionamento entre empresa e } \\
\text { cliente, que pode ser guiado por: conquistar } \\
\text { novos clientes, reter os atuais ou ampliar as } \\
\text { vendas. }\end{array}$ & $\begin{array}{l}\text { Qual tipo de relacionamento nosso } \\
\text { segmento de cliente espera que } \\
\text { estabeleçamos com ele? }\end{array}$ \\
\hline Fontes de Receita & $\begin{array}{l}\text { Meios de geração de capital financeiro no } \\
\text { modelo de negócio em desenvolvimento. }\end{array}$ & $\begin{array}{l}\text { Quais valores nossos clientes estão } \\
\text { dispostos a pagar e de que forma? }\end{array}$ \\
\hline Recursos principais & $\begin{array}{c}\text { Descrição dos recursos mais importantes para } \\
\text { começar o modelo de negócio, tais como: físico, } \\
\text { intelectual, humano ou financeiro. }\end{array}$ & $\begin{array}{c}\text { Quais os principais recursos } \\
\text { necessários para que a nossa } \\
\text { proposta de valor seja entregue como } \\
\text { planejado? }\end{array}$ \\
\hline Atividades principais & $\begin{array}{c}\text { Principais ações que a empresa precisa } \\
\text { desenvolver para a realização do seu modelo de } \\
\text { negócio. }\end{array}$ & $\begin{array}{l}\text { Quais as atividades-chave a nossa } \\
\text { proposta de valor reque? }\end{array}$ \\
\hline Parcerias principais & $\begin{array}{c}\text { Rede de fornecedores e parceiros que colocam } \\
\text { o modelo de negócio para funcionar. }\end{array}$ & $\begin{array}{c}\text { Quem são nossos principais parceiros } \\
\text { neste negócios? }\end{array}$ \\
\hline Estrutura de custos & $\begin{array}{l}\text { Todos os custos envolvidos na operação de um } \\
\text { modelo de negócio. }\end{array}$ & $\begin{array}{l}\text { Quais os custos mais importantes } \\
\text { envolvidos na operacionalização do } \\
\text { modelo de negócio proposto? }\end{array}$ \\
\hline
\end{tabular}

Nota: Elaboração própria a partir de Osterwalder e Pigneur (2011). 
Em outra perspectiva, Teixeira e Lopes (2016) utilizaram o BMC para descrever o modelo de negócio de duas instituições bancárias brasileira. Nesses casos, o modelo se mostrou eficiente na visualização da geração de valor das instituições. Já Morais, Glória, Costa e Gonçalves (2017) analisaram um projeto de inovação de uma grande empresa a partir de dois modelos Canvas, entre eles o BMC. Foi verificado que se os modelos tivessem sido aplicados no início do projeto alguns aspectos que não ficaram claros ou não foram considerados teriam sido previstos e contemplados durante a execução do projeto.

Observa-se que o BMC é um modelo criado para idealização de um negócio ou uma ideia (Osterwalder \& Pigneur, 2011). Entretanto, carece de mecanismos que possam dar continuidade aos projetos que podem ser originados a partir da concepção da ideia inicial, os quais colocarão em prática o que foi pensado. Assim, ressalta-se a necessidade de utilizar outras ferramentas complementares ao uso de um modelo baseado em Canvas (Finocchio Júnior, 2013, Veras, 2014, Gloria Júnior \& Gonçalves, 2016).

É nessa perspectiva que surge o Life Cicle Canvas (LCC). Essa ferramenta foi desenvolvida e apresentada por Veras (2016), que permite o gerenciamento de todo o ciclo de vida de projetos que podem auxiliar o empreendedor no desenvolvimento do modelo de negócio criado a partir do BMC.

\section{Life Cycle Canvas (LCC)}

O LCC apresenta uma base conceitual aderente às áreas de conhecimento do Project Management Body of Knowledge (PMBOK® Guide) (PMI, 2013), da metodologia PRINCE2 (Bentley, 2010), com aspectos relacionados ao controle de entregas e estruturas, e do Project Model Canvas (PMC), utilizando o conceito de gerenciar projetos em uma tela (Campelo \& Veras, 2016). Desse modo, o LCC apresenta uma proposta dinâmica e inovadora que une a ideia de ciclo de vida de projetos ao conceito de uso do canvas incorporando o acompanhamento do projeto em todas as fases do ciclo de vida: iniciação, planejamento, execução, controle e encerramento (Veras, 2016).

De forma a tornar a ideia do gerenciamento do ciclo de vida do projeto uma realidade, o LCC trata o canvas como uma saída de processos ligados ao gerenciamento de projetos alinhando a ideia sugerida pelo PMBOK (Veras, 2016). Além disso, o LCC incorpora o "movimento" entre as fases do projeto de forma que esse registro permeia todo o ciclo de vida do projeto. Nesse aspecto, a ferramenta torna-se dinâmica, pois permite que as telas sejam alteradas de forma simples ao longo do projeto com as informações inerentes a cada etapa, a saber: telas de Iniciação (IN) e Planejamento (PL); tela de Execução (EX); tela de Monitoramento e Controle (M\&C); e tela de Encerramento (EN) (Veras, 2016). Conforme o projeto avança as telas das fases anteriores são "congeladas” para manter o registro inicial e que possibilite um controle adequado das mudanças.

O canvas do LCC é formado por dois tipos de elementos: informações de interesse do projeto e fatores-chave. O primeiro elemento (informações de interesse do projeto) objetiva apresentar as informações básicas do projeto para que seja possível identificar facilmente o título, o status global da execução, a qual etapa do projeto a tela está associada, a versão, o local e data, bem como dados referentes ao gerente do projeto e a outras partes interessadas, como o patrocinador e o cliente. $\mathrm{O}$ segundo elemento (fatores-chave) é composto pelos por 15 caixas coloridas que estão associadas a técnica $5 \mathrm{~W} 2 \mathrm{H}$ e que representam essencialmente as áreas de conhecimento sugeridas pelo guia PMBOK (Veras, 2016). 
Na Figura 3 é apresentada a tela do LCC bem como seus componentes, e na Tabela 2 é demonstrado como se dá a associação com o $5 \mathrm{~W} 2 \mathrm{H}$.

As áreas de conhecimento sugeridas pelo Guia PMBOK são contempladas de forma direta, tais como: tempo, custos, riscos, compras, comunicações e partes interessadas, ou indiretamente, como: premissas, entregas e restrições (escopo), equipe (recursos humanos), e produtos e requisitos (qualidade). A área de conhecimento relativa à integração é contemplada por meio da relação entre os cinco grandes blocos diferenciados por cores e que devem ser construídos sequencialmente.

Outro aspecto inovador do modelo são os artefatos gerados pela tela. Esses artefatos são os mesmos sugeridos e induzidos pelo Guia PMBOK, a saber: termo de abertura do projeto (TAP), plano de gerenciamento do projeto (PGP), relatório executivo do projeto (REP) e relatório de solicitação de mudanças aprovadas (RMU) (Veras, 2016).

Em uma aplicação prática, Medeiros, Sousa Neto, Santos Nobre e Nogueira (2017) utilizaram o LCC para o planejamento de um projeto de infraestrutura pública de um governo estadual. No caso, demonstrado na Figura 3, foi observado que os participantes não tiveram dificuldades em entender a lógica do LCC e as atividades das etapas iniciais de gestão do projeto. Os resultados indicaram que existe aderência do LCC para o planejamento de projetos governamentais, em que as características inerentes aos projetos do setor público foram consideradas.

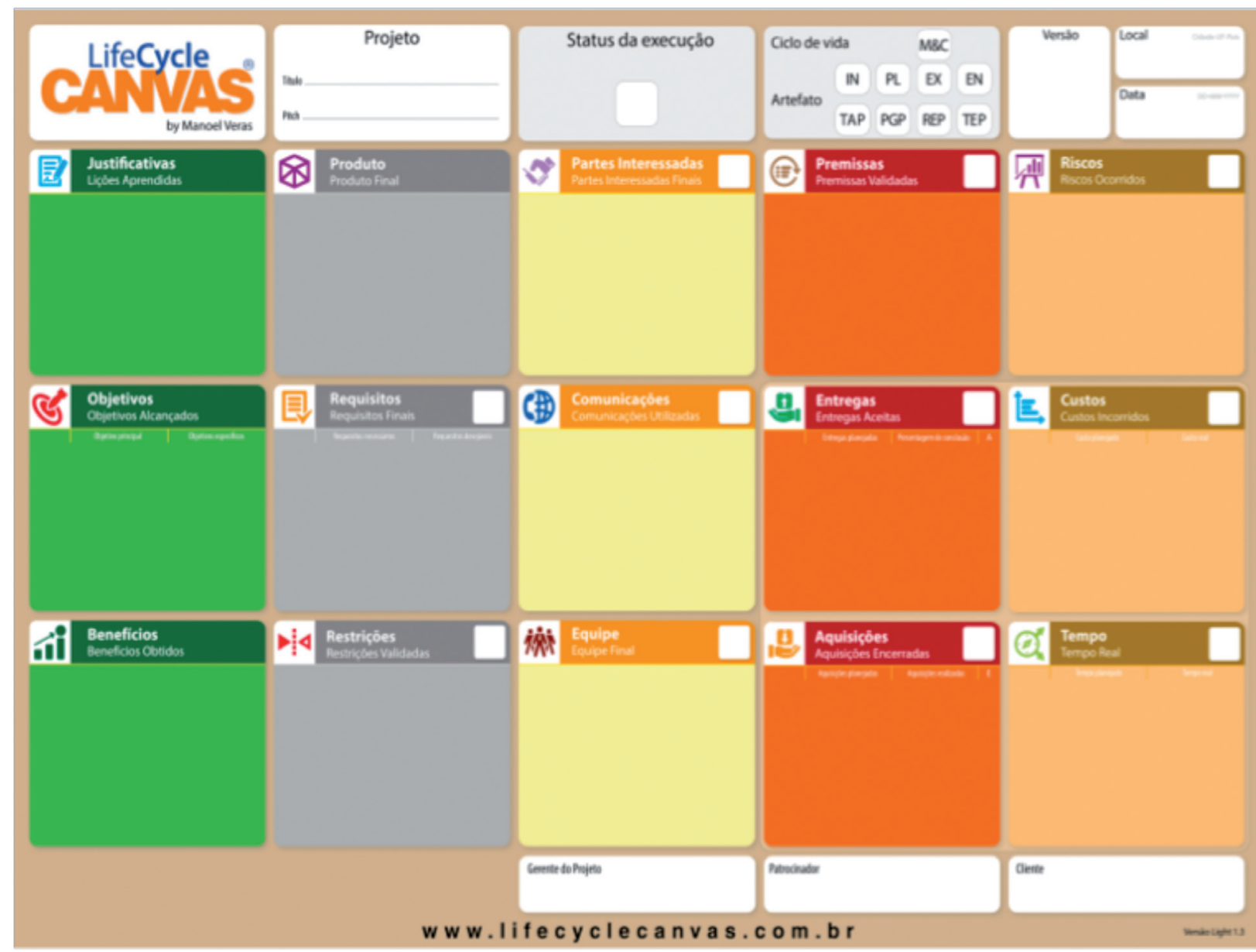

Figura 3: Modelo Life Cycle Canvas ${ }^{\circledR}$ (LCC)

Fonte: Veras, M. (2016). Gestão Dinâmica de Projetos: LifeCycleCanvas®. Brasport. 
Tabela 2: Tela do LCC associado ao 5W2H

\begin{tabular}{c|c|c|c|c}
\hline $\begin{array}{c}\text { Por quê? } \\
\begin{array}{c}\text { Razão de } \\
\text { existência do } \\
\text { projeto) }\end{array}\end{array}$ & $\begin{array}{c}\text { O quê? } \\
\text { (O que é o } \\
\text { projeto de } \\
\text { fato) }\end{array}$ & $\begin{array}{c}\text { Quem? } \\
\text { (Principais } \\
\text { agentes } \\
\text { envolvidos) }\end{array}$ & $\begin{array}{c}\text { Como? } \\
\text { (Explica as } \\
\text { condições } \\
\text { necessárias) }\end{array}$ & $\begin{array}{c}\text { Quando e } \\
\text { quanto? } \\
\text { (Riscos, datas } \\
\text { das entregas } \\
\text { e custos) }\end{array}$ \\
\hline $\begin{array}{c}\text { Justificativas } \\
\text { Lições aprendidas }\end{array}$ & $\begin{array}{c}\text { Produto } \\
\text { Produto final }\end{array}$ & $\begin{array}{c}\text { Partes } \\
\text { interessadas } \\
\text { Partes } \\
\text { interessadas finais }\end{array}$ & $\begin{array}{c}\text { Premissas } \\
\text { Premissas } \\
\text { validadas }\end{array}$ & $\begin{array}{c}\text { Riscos } \\
\text { Riscos ocorridos }\end{array}$ \\
\hline $\begin{array}{c}\text { Objetivos } \\
\text { alcançadivos }\end{array}$ & $\begin{array}{c}\text { Requisitos } \\
\text { Requisitos finais }\end{array}$ & $\begin{array}{c}\text { Comunicações } \\
\text { Comunicaçoses } \\
\text { utilizadas }\end{array}$ & $\begin{array}{c}\text { Entregas } \\
\text { Entregas aceitas }\end{array}$ & $\begin{array}{c}\text { Custos } \\
\text { Custos incorridos }\end{array}$ \\
\hline $\begin{array}{c}\text { Benefícios } \\
\text { Benefícios obtidos }\end{array}$ & $\begin{array}{c}\text { Restrições } \\
\text { Restrições } \\
\text { validadas }\end{array}$ & $\begin{array}{c}\text { Equipe } \\
\text { Equipe final }\end{array}$ & $\begin{array}{c}\text { Aquisições } \\
\text { Aquisições } \\
\text { encerradas }\end{array}$ & $\begin{array}{c}\text { Tempo } \\
\text { Tempo real }\end{array}$ \\
\hline
\end{tabular}

Nota: Adaptado de Veras (2016, p. 152).

Face ao exposto, observa-se que o LCC traz uma abordagem inovadora para gerenciar os projetos considerando a gestão de todo o ciclo de vida do projeto em telas. Assim, a próxima seção explora a associação desta ferramenta com o BMC, seguindo a lógica das fases do processo empreendedor.

\section{Associando o Business Model Canvas ao Life Cycle Canvas}

Para realizar a associação do BMC com o LCC, deve-se primeiro definir quais são os projetos prioritários. Nesse caso, será definido um portfólio de projetos que deverão ser executados primeiro. Segundo Veras (2014, p.69), “por mais que os projetos sejam estratégicos, os recursos e o tempo para realização são limitados. [...] A grande questão é como escolhê-los e com base em quais considerações".

Nessa perspectiva, deve-se considerar o risco do projeto, sabendo que a literatura indica que os empreendedores estão dispostos a correrem riscos calculados (Dornelas, 2011), e a contribuição estratégica para o negócio (Veras, 2014). Desse modo, pode-se considerar a utilização de uma matriz de priorização de projetos baseado nesses dois aspectos: riscos e contribuição estratégica.

A partir disso, um portfólio de projetos prioritários é definido para serem executados com o LCC. A Figura 4 ilustra um exemplo fictício em que vários projetos são gerados a partir da definição de um negócio com o BMC.

O exemplo ilustrado na Figura 4 é iniciado a partir da elaboração de um negócio a partir do BMC. Considerando que esta parte inicial de idealização e planejamento do negócio corresponde as duas primeiras fases do processo empreendedor, são nestas fases que serão gerados os projetos estratégicos para criação ou implementação do negócio. Na Figura 4, esses projetos foram ilustrados nos seguintes componentes do BMC: parcerias (Projeto 1); relacionamento (Projeto 2); segmento de clientes (Projeto 3); canais (Projeto 4); recursos (Projeto 5); e fontes de receita (Projeto 6).

Em seguida, esses projetos são selecionados em uma matriz de priorização, considerando os fatores risco e contribuição estratégica. A partir dessa análise é definido um portfólio de projetos prioritários. Para fins de ilustração os projetos $3 \mathrm{e}$ 5 indicaram a melhor relação na matriz de priorização e foram selecionadas para serem executados com o LCC.

Com isso, a exemplo dos projetos 3 e 5 , extraídos do BMC (Figura 4), os mesmos podem ser gerenciados de forma dinâmica, com respostas rápidas e possibilidades de alteração, gerando flexibilidade, corroborando com o que foi relatado por Nagamatsu, Barbosa e Rebecchi (2014).

Em se tratando das vantagens na utilização dos dois modelos, destaca-se a possibilidade de 


\section{Fases do Processo Empreendedor}

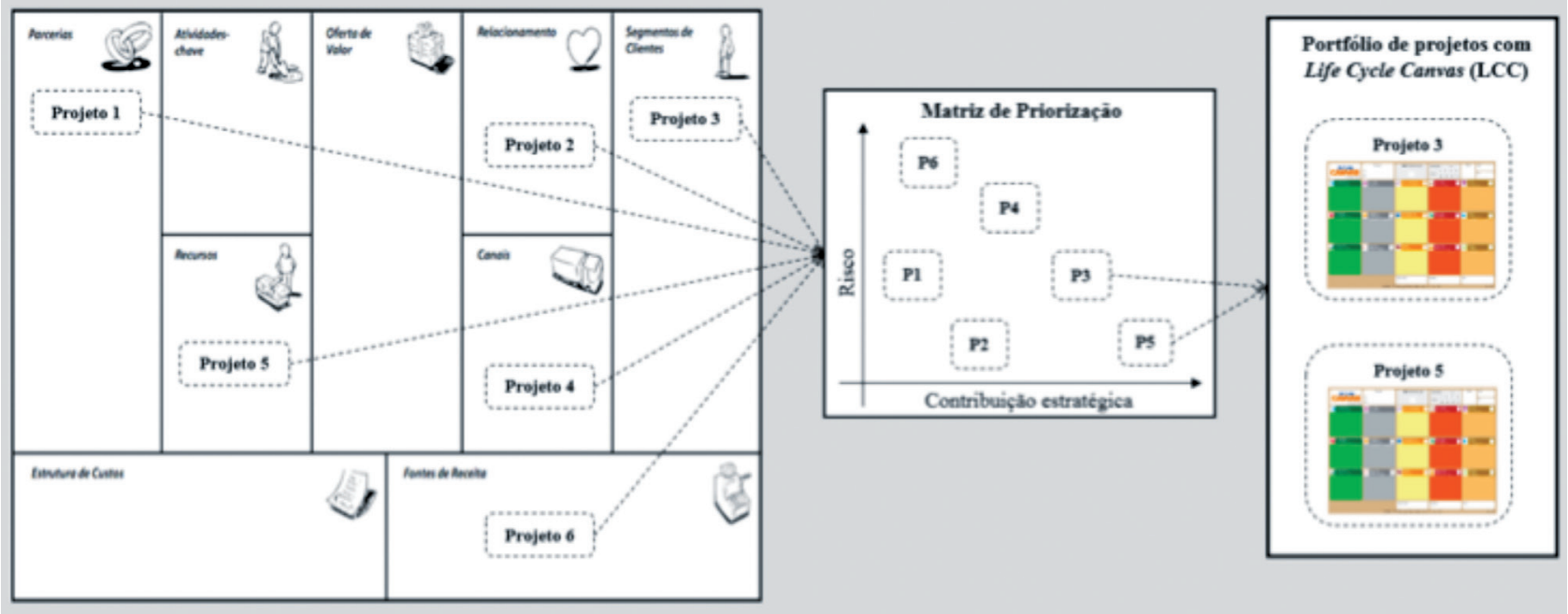

Figura 4: Associação do BMC com o LCC

Fonte: Elaborado pelos autores.

se aplicar mais de um modelo e a combinação com outras metodologias (GLÓRIA JÚNIOR e GONÇALVES, 2016) possibilitando uma melhor gestão do portfólio de projetos, além da flexibilidade e interatividade dos quadros visuais.

Cabe ressaltar que estes projetos podem estar relacionados com a própria definição dos componentes do BMC. Por exemplo, se for preciso fazer um estudo de mercado para definição clara dos segmentos de clientes o projeto também estaria relacionado à primeira fase de idealização do negócio.

A Tabela 3 indica alguns aspectos de complementaridade entre as duas ferramentas. De modo geral, fica claro que o escopo do BMC está relacionado à fase de iniciação do negócio ou de um projeto o LCC fornece meios para que gerenciamento e controle dos projetos.

Portanto, com base na proposição de utilização de canvas em complementaridade, ou seja, que possam ser utilizados concomitantemente, ou seja, o processo empreendedor se iniciará com o uso do canvas aplicado ao negócio (BMC) e terá como etapa seguinte a utilização de um outro can-
Tabela 3: Aspectos de complementaridade do BMC associado ao LCC

\begin{tabular}{c|c}
\hline BMC & BMC ALINHADO AO LCC \\
\hline $\begin{array}{c}\text { Envolve apenas a } \\
\text { fase de iniciação do } \\
\text { projeto. }\end{array}$ & $\begin{array}{c}\text { Permite acompanhamento } \\
\text { de todo o ciclo de vida dos } \\
\text { projetos originados no BMC. }\end{array}$ \\
$\begin{array}{c}\text { Não contempla a } \\
\text { gestão da mudança. }\end{array}$ & $\begin{array}{c}\text { É possível gerenciar as } \\
\text { mudanças que ocorrem } \\
\text { naturalmente no decorrer do } \\
\text { projeto. }\end{array}$ \\
\hline $\begin{array}{c}\text { Não permite } \\
\text { comparações do } \\
\text { planejado com } \\
\text { o executado, } \\
\text { sem registros de } \\
\text { aprendizagem e } \\
\text { melhoramento. }\end{array}$ & $\begin{array}{c}\text { Sugere no encerramento } \\
\text { de cada entrega uma } \\
\text { comparação entre o } \\
\text { planejado e o executado, } \\
\text { e apresenta um campo das } \\
\text { lições aprendidas neste } \\
\text { processo. }\end{array}$ \\
$\begin{array}{c}\text { Define os } \\
\text { objetivos, mas sem } \\
\text { detalhamento ou } \\
\text { desdobramento em } \\
\text { projetos ou ações. }\end{array}$ & $\begin{array}{c}\text { Desdobra um objetivo } \\
\text { principal em várias } \\
\text { entregas, o que permite a } \\
\text { operacionalização da ideia. }\end{array}$
\end{tabular}

Fonte: Elaborado pelos autores.

vas para a gestão dos projetos gerados a partir do negócio (LCC).

A utilização de múltiplas ferramentas já foi citada anteriormente (Nagamatsu, Barbosa \& Rebecchi, 2014) se apresenta como uma opção efetiva para o sucesso na execução dos projetos oriundos da definição inicial do negócio, em face 
da complexidade e da variabilidade no uso de ferramentas para a gestão dos projetos, estando a concepção do LCC alicerçada nas melhores práticas mundiais.

\section{Considerações finais}

$\mathrm{O}$ artigo teve como objetivo propor uma associação do modelo BMC com o LCC, indicando a complementaridade entre essas duas ferramentas para gerar um artefato que pode ser utilizado durante o processo empreendedor. Observou-se que estas duas ferramentas se tornam complementares quanto ao seu uso, pois uma está focada na definição do negócio (BMC) e a outra na gestão dos projetos (LCC).

Portanto, os dois modelos visuais podem ser associados a uma ferramenta de seleção e priorização de projetos, como metodologia complementar, para que se possa obter um melhor desempenho no processo de gestão.

Com isso, a gestão visual do negócio sai da fase de ideação ou planejamento (BMC) e explora a gestão dos projetos (LCC), gerando um caráter de continuidade na gestão por meio de modelos visuais que podem ser considerados complementares em sua funcionalidade para as organizações.

Do ponto de vista das contribuições práticas, este artigo oferece subsídios iniciais para que os gestores percebam as possibilidades de utilização de mais de um canvas nas organizações, desde a visão do negócio até a gestão dos seus projetos, até então vistos de forma isolada, sem uma possibilidade de dispor de um artefato que auxilie o empreendedor ao longo da sua jornada empreendedora.

Ainda se faz necessário destacar as limitações do estudo. A primeira reside no fato deste apresentar apenas uma proposta teórica. A aplicação prática viria a ratificar as proposições aqui desenvolvidas. A opção pelo artigo teórico se deu justamente por não ser possível, ainda, identificar uma organização que já possuísse essa forma de atuar na prática.

A título de sugestões para estudos posteriores, este artigo pode ser desdobrado em aplicações práticas, em estudos de casos reais de uso das duas ferramentas, bem como em outros estudos que promovam a integração do LCC com outros canvas ou ferramentas de gestão.

\section{Referências}

Baron, R. A., \& Shane, S. A. (2010).

Empreendedorismo: uma visão do processo. Cengage Learning.

Bentley, C. (2010). Prince2: a practical handbook. [New York]: Routledge.

Campelo, B., \& Veras, M. (2016). Life CycleCanvas: gestão dinâmica de projetos. Mundo PM, 70, 70-76.

Carrasco, L. C., Souza Nunes, M. A., Cerqueira, C. E. M., \& Costa Rosas, T. M. (2014). Uma análise da aplicação do Business Model Canvas-BMC a partir da visão de empreendedores que se encontram em diferentes fases do negócio-uma experiência da incubadora de empresas e projetos do Inatel. In: XXIX Seminário Nacional de Parques Tecnológicos e Incubadoras de Empresas, Belém, PA, Brasil.

Dornelas, J. C. A. (2011). Empreendedorismo: transformando ideias em negócios. Elsevier-Campus.

Finocchio, J., Jr. (2013). José. Project Model Canvas: gerenciamento de projetos sem burocracia. Elsevier Editora.

Gloria I. Jr, \& Gonçalves, R. F. (2016, outubro). As barreiras e motivações para o uso da abordagem canvas. In: XXXVI Encontro Nacional de Engenharia de Produção, João Pessoa, PB, Brasil.

Hrebiniak, L. G. (2006). Obstacles to effective strategy implementation. Organizational dynamics, 35(1), 12-31.

Jamieson, A., \& Morris, P. W. (2007). Moving from corporate strategy to project strategy. In: The Wiley Guide to Project, Program, and Portfolio Management (pp. 34-62). John Wiley \& Sons Hoboken, NJ.

Kwak, Y. H., \& Anbari, F. T. (2009). Analyzing project management research: Perspectives from top management journals. International Journal of Project Management, 27(5), 435-446. 
Medeiros, B. C., Sousa Neto, M. V., Santos Nobre, A. C., \& Nogueira, G. M. F. (2017). Planejando projetos com o Life Cycle Canvas (LCC): um estudo sobre um projeto de infraestrutura pública estadual. Exacta, 15(1), 155-170. https://doi.org/10.5585/exactaep.v15n1.6947

Mei, P. (2015). PM Mind Map®: A gestão descomplicada de projetos. Rio de Janeiro: Brasport.

Morais, M. O., Glória, I. Jr., Costa, P. L. O. Neto, \& Gonçalves, R. F. (2017). Análise de um projeto de inovação tecnológica e o uso da abordagem Canvas. Iberoamerican Journal of Project Management, 8(1), 14-26. http://www.ijopm.org/index.php/IJOPM/article/ view/299

Nagamatsu, F. A., Barbosa, J., \& Rebecchi, A. (2014). Business model generation e as contribuições na abertura de startups. In: II Simpósio Internacional de Gestão de Projetos (SINGEP), São Paulo, SP, Brasil.

Osterwalder, A., \& Pigneur, Y. (2011). Business model generation: inovação em modelos de negócios. Alta Books Editora.

Project Management Institute (2013). Um guia do conhecimento em gerenciamento de projetos (guia PMBOK®). (5a ed.). São Paulo: Saraiva.
Schumpeter, J. (1985). O fenômeno fundamental do desenvolvimento econômico. In: A teoria do desenvolvimento econômico. Rio de Janeiro: Nova Cultural.

Serviço Brasileiro de Apoio às Micro e Pequenas Empresas - Sebrae. (2013). Cartilha o Quadro de Modelo de Negócios: um caminho para criar, recriar e inovar em modelos de negócio. Recuperado em 7 novembro, 2017, de http://www.sebrae.com.br/Sebrae/Portal\%20 Sebrae/Anexos/Cartilha\%20o\%20Quadro\%20do\%20 Modelo\%20de\%20Negocios.pdf.

Teixeira, L. C. M., \& Lopes, H. E. G. (2016). Aplicação do modelo canvas para o modelo de negócios do Banco do Brasil e da Caixa Econômica Federal. Revista Gestão \& Tecnologia, 16(2).

Veras, M. (2014). Gerenciamento de projetos: Project Model Canvas (PMC). Brasport.

Veras, M. (2016). Gestão dinâmica de projetos: LifeCycleCanvas®. Rio de Janeiro: Brasport.

Zandoval Bonazzi, F., \& Ari Zilber, M. (2014). Innovation and Business Model: a case study about integration of Innovation Funnel and Business Model Canvas. Revista Brasileira de Gestão de Negócios, 16(53), 616-637.
Recebido em 12 out. 2017 / aprovado em 28 nov. 2017

\section{Para referenciar este texto}

Silva Filho, A. M., Silva, R. R., Silva, \& D. C.

Medeiros, M. F. M. O processo empreendedor: associando o Business Model Canvas (BMC) ao Life Cycle Canvas (LCC). Exacta, São Paulo, v. 16, n. 4, p. 35-44. out./dez. 2018. Disponível em: <https://doi. org/10.5585/ExactaEP.v16n4.7991> 